\title{
A SOCIABILIDADE ENTRE JOVENS ATRAVÉS DO HEAVY METAL
}

\author{
Luana Cristina Seixas ${ }^{1}$
}

\section{Resumo}

O presente trabalho pretende uma abordagem introdutória à socialização de jovens no estilo musical Heavy Metal. Partindo de questões postas pela Antropologia e a Sociologia à "juventude" enquanto questão social ou cultural, aborda a relação entre jovens e música da perspectiva da construção de "juventudes" e chega ao tema da socialização no "metal". A partir de uma rápida introdução ao estilo Heavy Metal, propõe questões formuladas na relação entre juventude(s) e Metal, tais como a sensibilidade relacionada à escuta de sons "pesados", a hierarquia interna ao universo dos fãs, a relativização da noção de "juventude" e a interação entre gerações de "metaleiros".

Palavras-Chave: Juventude; Música; Heavy Metal; Sociabilidade.

${ }^{1}$ Mestra da Pós Graduação em Ciências Sociais na Universidade Federal de Juiz de Fora 


\section{1 - Introdução:}

Ao pensarmos na categoria 'juventude' nas ciências sociais precisamos reconhecer a variedade de experiências da juventude, o que torna mais adequado o uso do termo no plural, assim como usado por Dayrell (2003) e muitos outros autores. Dayrell distingue a juventude como uma fase em construção (não maturação), mais densa que uma "fase de passagem". Trata-se de uma "fase de transição", a qual o jovem está em formação, e convive com questões existenciais mais complexas do que a passagem para a vida adulta. Portanto, ele percebe a fase da juventude como elemento de um processo mais vasto de construção de sujeitos.

Na obra "Juventude e Contemporaneidade" (2007), Helena W. Abramo (1997) descreve como a juventude vem sendo analisada e estudada a partir dos anos 1950. Nos anos 50, o problema social da juventude estava relacionado à figura dos "rebeldes sem-causa", como uma fase da vida complicada e agitada e cabia aos adultos guia-los para uma melhor integração à sociedade. Nos anos 60 e parte dos anos 70, o problema aparece através da imagem dos jovens como ameaçadores da ordem social como uma forma de crítica e busca por transformação, dando início aos movimentos de contracultura como o movimento hippie.

Diferente dos anos 60, nos anos 80 a juventude é marcada como individualista, conservadora e apática aos contextos públicos. Incapaz de afrontar ou apresentar soluções a fim de modificar ou reparar as disposições negativas do sistema. E por último, a obra cita os anos 90 como a década em que os jovens estão relacionados à violência e ao desvio, representados como meninos de rua, infratores, gangues, ou seja, jovens como risco para si e para a ordem social. Depois da década de 90 inicia-se uma preocupação quanto a agrupar a categoria juventude com outras categorias.

Acategoriajuventude pode ser combinada com outros indicadores como classe, gênero, cor, sexualidade e religião, resultando em especificidades marcantes no vivenciar a "juventude". Desta forma, as ciências sociais demonstraram que a juventude é uma construção social. E de acordo com Assis (2005, p.56) "o recorte geracional marca experiências sociais e históricas distintas e em tensão entre uma geração anterior (jovem) e uma posterior (adulta)".

Pais (2003, p.71) também entende o indicador geracional de extrema importância, sendo preciso refletir sobre a juventude levando em consideração a perspectiva geracional e de classe em suas diferentes condições, interesses 
e gostos. A partir das relações entre jovens ao compartilharem esses mesmos interesses e das circunstâncias oferecidas na estrutura social. Giddens (1989) observa, por sua vez, como esse processo que determina a vivência da juventude, constantemente é criado pela mídia ou por instituições, pela ação do conhecimento mútuo, o qual se divide em um "conhecimento de base", ou seja, um conhecimento adquirido, (não concluído, mas que pode ser empregado na interação), e um conhecimento constantemente inovado e transformado no proceder da interação.

Nesse sentido, os estudos sobre juventude deixam de se ater a "fases da vida", infância, adolescência e vida adulta para pensar a juventude enquanto condição do indivíduo, ou um modo particular de se relacionar com a sociedade, que varia segundo os indicadores já mencionados. A compreensão de juventude na sociologia é baseada na esfera social na fase da vida entre a infância e a vida adulta, em que os jovens se integram e se constituem como um membro da sociedade através da cultura e o acolhimento das regras de comportamento da vida adulta. Trata-se de um "momento crucial para a continuidade social: é nessa oportunidade que a integração do indivíduo se efetiva ou não, trazendo consequências para ele próprio e para a manutenção da coesão social" (Novaes: 2007:79). Dessa forma, a juventude se torna um problema para as ciências sociais. Trata-se de uma problematização moral com atenção voltada para a coesão moral e para a integridade moral do indivíduo.

A música assume papel crucial no "ser jovem" nas sociedades contemporâneas. Como observa Margarete Arroyo (2013, p.17): "Se a música é a parceira de destaque nessa fase da vida, então convém saber como ela participa das inúmeras possibilidades de ser jovem e de viver a juventude nas sociedades contemporâneas". A adolescência é, então, um processo de construção dos sujeitos através de estilos de vestes, inclusão em grupos e estilos musicais, em que estes se reconhecem e reconhecem os outros.

Ao compartilhar dos mesmos interesses e gostos, o jovem experimenta, através da música, o sentimento de compartilhamento. A música permite a construção de uma juventude, de uma identidade ou "estilo-de-ser-jovem". Além de ser uma ferramenta de obtenção de lazer é também de integração social, como uma forma de delimitar as diferenças e semelhanças socioculturais, auxiliando na criação de grupos e na reflexão sobre "quem o indivíduo é" e "quem é igual ou diferente dele". A música estabelece trocas, experiências e construção de identidades pessoais e de distintas maneiras de ser jovem, ou seja, a música influi 
na construção de identidades, pois auxilia o indivíduo a interpretar aos outros e a si mesmo. A troca de conhecimento acontece de modo particular, por meio de procedimentos informais de troca de informação "boca-a-boca" entre amigos e membros do grupo dentro da cena Heavy Metal.

\section{2 - Música e Juventude}

A música é um instrumento central de experiência juvenil, como um meio de comunicação similar a língua, pois possui seus próprios códigos e símbolos. Isto serve para muitas experiências, ou seja, em diversos gêneros musicais. A música é o canal de construção dos gostos e preferências destes jovens e reúne diversos elementos culturais, aos quais os indivíduos se reconhecem ou não. Neyde Carstens Martins Pelaez (2005) faz um estudo etnográfico que explora o universo musical dos adolescentes de uma escola luterana na cidade de Joinvile. Esses jovens possuem idade na faixa de 12 anos e distinguem com quais músicas se identificam, ou seja, por meio do interesse de determinados gêneros musicais, compartilham estilos de vida e concepções de mundo, estabelecendo assim limites de sociabilidades ao se identificarem.

Pelaez (2005) identificou uma discriminação por parte de alguns alunos em relação às preferências musicais de alguns colegas, o que produz acanhamento de alguns jovens ao comentarem a respeito, daí a necessidade de aplicar questionários para serem respondidos em casa, porém poucos alunos devolveram estes questionários respondidos. Foi possível verificar o que estes jovens entendem por música e a partir daí entender a preferência de gênero musical de cada aluno. Pelaez conclui que a escolha da música está relacionada a diversos fatores. Como por exemplo, gênero, já que as músicas que desencadeiam a ação de dançar demonstram que esta música está ligada à representação do feminino, uma vez que os meninos afirmam não gostar de dançar. A autora não faz distinção de quais gêneros musicais estão atrelados à dança para essa análise de gênero. Para entender essa distinção entre masculino e feminino ligado às preferências musicais seria necessário aprofundar a análise sobre as dinâmicas culturais relacionadas à música.

Outro elemento descrito na obra é a letra das músicas, elemento decisivo na preferência musical. $\bigcirc$ exemplo que encontramos nesta mesma dissertação de mestrado são as letras das músicas sertanejas, as quais abordam a vida no Sertão e a criação de gado, ambiente distante do espaço social destes alunos, os quais 
estabelecem o espaço urbano como desenvolvido e o rural como "atrasado", daí a rejeição desses alunos em relação a este gênero musical. Portanto, podemos perceber uma hierarquia quanto aos gostos musicais devido ao interesse por determinado gênero musical, relacionada assim a manifestação de identidade.

Fernandes \& Freire Filho (2005) reconhecem que os pesquisadores da Escola de Birmingham afirmavam que as "interpretações ideológicas" somente determinavam a identidade da cultura dos jovens através da música, estilos e lazer em uma "cultura paterna", a qual os adolescentes eram um fragmento da "cultura dominante" e a "cultura de massa" e as diversidades entre as distintas camadas de juventude. Além de indicadores de hábitos de consumo adquiridos através do lazer e da moda juvenil, representavam "soluções" culturais dos jovens em resposta às dificuldades relacionadas à sua experiência influenciada pela classe, etnia, geração e gênero.

Amanda Veloso Garcia (2013) contribui com o estudo de música, no sentido de narrar a história da Etnomusicologia. No início, buscava-se descobrir a estrutura da música, identificando seus tons e ritmos, depois a reflexão sobre música nos termos "o que é música?" passa para "por que a música é deste modo?", dando surgimento a Etnomusicologia anteriormente chamada de "Musicologia Comparada", a qual busca entender os fenômenos culturais que desencadearam determinado comportamento musical. Ao passo que a Musicologia se interessa com o texto musical, a Etnomusicologia se preocupa com o contexto no qual a música está colocada, ou seja, o porquê da música ser de determinada maneira. A música é culturalmente apreendida e socialmente executada através de troca de conhecimento.

Sendo assim, a música propicia a comunicação e a interação entre os indivíduos, estes adquirem o comportamento e a estética com o meio social, e por isso a música não pode ser analisada apenas como objeto fabricado, mas como desencadeadora de comportamentos específicos vinculados a cada gênero musical.

\section{3 - Juventude e Metal}

O Heavy Metal tem sua origem na Inglaterra e nos EUA na década de 1970. De início, associava-se a classes operárias e áreas em processo de crise e desemprego, o que transparecia nas temáticas sociais e políticas nas letras (Leite Lopes, 2006, p.04). Este cenário se transformaria em algumas décadas, com a 
adesão ao gênero de jovens e adolescentes de camadas médias e com a difusão global do Heavy Metal. As características musicais e estéticas deste gênero musical são:

a guitarra hiper distorcida, grave nos refrões das músicas, ou "riffs" (utilizando os chamados "power chords", acordes geralmente de duas notas graves, num intervalo de uma quarta ou uma quinta, obrigatoriamente com o efeito de distorção, que produzem acusticamente tons resultantes, gerando mais que as duas notas tocadas, segundo Walser, 1993:4323) e aguda nos muitas vezes longos e hiper velozes solos; o baixo tocado nas cordas mais graves e geralmente veloz; a bateria rápida e tocada de maneira vigorosa, geralmente com mais peças que em outros gêneros; os vocais emotivos e agressivos, muitas vezes também com um elemento de distorção; a extrema altura do som em shows e em audições privadas; as temáticas das letras políticas, anti-belicistas, sobre desajuste social, com alertas contra o abuso de álcool e outras drogas, hedonistas ou clamando ou festejando a noção de "liberdade", místicas, sombrias, satânicas, de fantasia; as roupas pretas, os cabelos longos e as tatuagens de músicos e fãs e uma atitude de "proud pariah" (Deena Weinstein, 2000:93 apud Lopes, 2006, p.25-26)

O Heavy Metal estabelece uma figura estética e comportamental, criando identidades particulares, no qual indivíduos se tornam headbangers ${ }^{2}$ por meio das relações sociais travadas. Além disto, aprendem também a desenvolver uma crítica musical quanto a maneira que a música é executada, desenvolvendo assim uma sensibilidade musical. Oliveira Júnior (2011, p.07) descreve o Heavy Metal como dotado de letras, maneiras de tocar os instrumentos, arranjo, harmonia, ritmo, melodia próprias do grupo e o adolescente ao viver e obter experiência musical estabelece uma sociabilidade através dessas caraterísticas. Diante disso, que sociabilidade juvenil metaleira é essa? Quais valores e comportamentos estão implicados neste grupo?

Pensando o Heavy Metal como um gênero musical urbano com seu início no Brasil datado na década de 1980, quem são esses jovens metaleiros? Lopes (2006) observa que no Brasil, o Heavy Metal inicialmente predominavam

\footnotetext{
${ }^{2}$ No Brasil, metaleiro é o termo utilizado para designar um fã de Heavy Metal, também chamado de headbanger e metalhead (termo mais utilizado na Europa), pois remete ao ato de "bater cabeça", também chamado de banguear, o qual consiste em vibrar com determinada música ou som, movimentando a cabeça de acordo com o ritmo.
} 
indivíduos jovens de sexo masculino brancos de camadas médias intermediárias e de pequena classe média dos grandes centros urbanos devido ao capital imprescindível para a compra de CDs, discos importados e fitas cassetes. Se antes era preciso acesso aos discos importados, a partir do uso difundido da internet foi possível substituí-los parcialmente por arquivos digitais. Diante das mudanças ocorridas seria prudente pensar os metaleiros pertencentes a diferentes classes.

Há uma predominância de homens brancos ainda que as mulheres, aos poucos venham se destacando, seja em sua presença como público ou como integrante de bandas. Quanto à faixa etária, a maioria dos indivíduos é jovem e os mais novos possuem 15 anos, mas encontramos um número considerável de indivíduos com idade superior a 40 anos e estes possuem prestígio diante dos mais jovens, pelo seu conhecimento e sua vivência no Metal. A propósito, a faixa etária torna-se um problema conceitual para a noção de "juventude" como veremos mais adiante.

Lucas Lopes de Moraes (2013) ao pesquisar a cena Black Metal em São Paulo, ou seja, uma vertente ou subgênero do Heavy Metal descreve o perfil do metaleiro entre os 16 aos 50 anos. Entretanto, em outros trabalhos observase que a maior parte seria composta por jovens de 15 a 25 anos, pois a adesão ao gênero musical se dá enquanto adolescente. Período o qual estes indivíduos buscam romper com tudo aquilo que os envolviam na infância e tendendo para uma construção de identidade através de amigos. A iniciação ocorre através de parentes e amigos, estes são os responsáveis pela introdução dos jovens no seu desenvolver da percepção e apreciação da música, estabelecendo contatos e grupos de reconhecimento.

Dentre os trabalhos sobre Heavy Metal destacam-se os estudos de Deena Weinstein (2000) sobre diversos elementos do gênero Heavy Metal no mundo, como letra, fãs e vestimentas como também a constante negociação e conflitos entre público, gravadoras, músicos, críticos musicais e mídia voltada para uma faixa indistinta de consumidores.

A pesquisa de Keith Kahn-Harris (2007) pensa a cena do subgênero Metal Extremo como um ambiente no qual os componentes do grupo utilizam temáticas destrutivas em suas letras, no entanto compartilham dos prazeres do grupo através da amizade. E por último, Natalie Purcell (2003) que questiona alguns elementos dirigidos ao público do subgênero Death Metal como censura, violência e religião. Todos os autores citados recorreram à categoria juventude para dar início aos seus estudos sobre o público Heavy Metal ou sobre algum 
subgênero relacionado a este.

\section{4 - Socialização no Metal}

A identidade proporciona a interação entre os indivíduos pertencentes ao grupo, através do entrosamento e o compartilhamento do mesmo gosto musical por meio da comunicação. O convívio possibilita a fluidez constante de informação e de laços de amizade. A música também é um elemento importante de motivação e agregação desse grupo contribuindo para a sociabilidade, a música é assunto nas conversas tantos nos encontros como na internet e também é produtora de identidades e de consumo de componentes estéticos atrelados ao Heavy Metal como roupa e estética corporal. Os elementos proporcionados por este gênero se tornam particular, diferenciando-se dos demais gêneros musicais e sendo reconhecido pelos seus semelhantes. Os metaleiros se distinguem dos demais grupos pela sua maneira específica de se comportar e vestir, sendo assim, os indivíduos produzem suas vivências a partir do Heavy Metal e dos conceitos construídos pelo gênero.

A iniciação no Metal ocorre principalmente na fase da adolescência, na escola e ou na família por intermédio de um indivíduo mais velho. Hoje com o acesso mais fácil à internet e a mídia, o jovem tem a oportunidade de conhecer e procurar bandas ainda desconhecidas por este, mas devido ao grande número de bandas existentes, o amigo ou parente mais velho continua sendo de grande importância na iniciação dos adolescentes no Metal. Este indivíduo mais velho apresenta as bandas clássicas, as músicas mais famosas e seus "melhores álbuns". Gostar de Heavy Metal não envolve apenas escutar música, vestir e se comportar de acordo com o grupo como já descrito anteriormente, mas também pesquisar na internet ou em revistas informações sobre as bandas e os seus integrantes.

Patrícia Rodarte Silva Gomes Coelho (2014, p.13) em sua Dissertação de Mestrado em Educação narra a sua inserção no Heavy Metal e a sociabilidade dos membros deste grupo ao analisar a educação estética e política da cena Metal na cidade de Belo Horizonte:

Desde os 12 anos de idade, eu já me interessava pela música do gênero heavy metal. Ouvia a Rádio Terra FM na época, gravava fitas cassete, comprava discos. O que me chamava atenção era aquele som pesado, com distorções, além do visual diferente, das roupas pretas, com acessórios de metal, cabelos 
compridos usados pelos caras, além das capas dos álbuns com ilustrações de caveiras e ou ambientes sinistros, sombrios. Havia um ambiente de encontro e sociabilidade "heavy metal" na porta da loja Cogumelo Discos nos sábados, principalmente. Surgia ali uma expressão estética diferente do convencional , uma nova proposta de um estilo musical que me conquistava. Mas o que marcou mesmo foi o primeiro show de uma banda classificada como banda de hard rock, a Banda Kiss em Belo Horizonte. Ainda que não diretamente do gênero heavy metal, mobilizou muitos jovens para conhecer quem eram aqueles integrantes com rostos pintados, cabelos grandes, roupas diferentes, que pareciam de super heróis, botas de plataforma.

A autora continua seu relato contando como mantém laços com o Heavy Metal até a sua vida adulta:

Sendo assim, esta identificação ao estilo vem me acompanhando ao longo da vida, criando cada vez mais interesse com a música e os desdobramentos que o heavy metal constitui. Mesmo depois dos 30 anos de idade, continuo fiel ao estilo, usando camisetas das bandas, comprando e ouvindo os CDs, indo aos shows e procurando saber mais sobre a historiografia do heavy metal. (Coelho, 2014, p.14)

Campoy (2008) aborda a diferença na vivência dos metaleiros jovens e mais velhos em relação ao Heavy Metal. Como o fã se envolve a ponto de levar o seu gosto musical para todos os âmbitos e cada vez mais deseja fazer parte deste grupo, seja como público ou como integrante de alguma banda. Os metaleiros mais velhos tem a chance de reviver sua adolescência, encontrar com amigos do mesmo cenário, claro que seu comportamento sofreu mudanças. E seus movimentos com a cabeça e com o corpo são mais contidos, mais seletivos quanto às escolhas dos shows a frequentar e bandas a conhecer. Nos shows é frequente a presença de indivíduos mais jovens (adolescentes) e também de indivíduos mais velhos que relembram sua adolescência/juventude através do Metal.

O fã não é apenas consumidor, pois ele busca vivenciar e experimentar o Heavy Metal. O metaleiro tem o desejo de fazer parte e contribui para a cena, frequentando assiduamente aos shows de bandas de amigos e criando a sua própria banda de garagem. De início tocando cover, ou seja, músicas conhecidas de bandas famosas e posteriormente compondo suas próprias músicas. Depois 
de realizar shows com equipamento de som de má qualidade em lugares precários que acomodam um público pequeno e, decidem investir em gravações de suas músicas próprias. O sentimento de pertencimento por meio do gosto musical compartilhado se torna mais intenso nesses momentos. Todo o público canta em apenas uma voz os sucessos da banda. A banda cria sua página no Facebook, Instagran, Myspace, Twitter e Youtube para divulgar a agenda dos shows e postar músicas e vídeos da banda. Atualmente existe uma preocupação quanto à gravação de vídeo clipes por parte das bandas por uma questão de inovação e maturidade em conseguir gravar um vídeo clipe de boa qualidade.

Pensando ainda na interação através da internet, existem ainda concursos no Facebook em que as bandas se inscrevem e a banda que compartilhar mais vezes o evento tem a oportunidade de tocar em uma determinada noite nessa casa noturna, e a partir disso a publicação é compartilhada por todos os amigos e parentes. Uma forma de ajudar as bandas a concorrer à chance de tocar, e ajudar a casa noturna a divulgar o evento. Esses eventos ainda contam com promoções como "se compartilhar o evento e marcar dois amigos concorre a um ingresso VIP e um drink" e assim mais postagens sobre o evento aparecem nas linhas do tempo do Facebook.

O Heavy Metal ganha proporção e se torna um fator de agregação social. O fã está presente nos shows de bandas famosas consagradas e de bandas de amigos, compra CD, DVD e camisa. Adota as vestimentas caraterísticas do Metal como jaquetas e calças jeans rasgadas ou de couro na cor preta, deixa o cabelo crescer, tem tatuagens, piercing e alargadores. Torna-se frequentador de lugares de encontro de fãs de Heavy Metal, como bares, casas de show e lojas de artigos deste gênero. É dessa maneira que o metaleiro vivencia o Heavy Metal.

Existe uma sociabilidade local entre os jovens através do compartilhamento de gostos e idas a shows na cidade e outros estados em uma experiência concreta, como também uma sociabilidade internacional ligada ao conhecimento de bandas clássicas e novas do mundo inteiro. Ambas as sociabilidades utilizam a internet como ferramenta.

Para esses jovens é essencial o encontro para que assim sejam trocadas histórias, experiências e informações sobre as novidades do cenário Heavy Metal, seja esse encontro pessoalmente ou através de conversas virtuais. As redes sociais têm se tornado uma ferramenta para marcar encontros com os adeptos, conhecer o som de bandas de amigos, os quais enviam o link do vídeo ou áudio de sua conta no Youtube e também para a divulgação de eventos de 
Heavy Metal em diferentes locais. Dessa maneira, a comunicação é essencial para manter essas relações.

A internet facilitou o acesso às músicas, clipes e shows, as compras de ingressos de shows em outra cidade, estado e as trocas de conhecimento relacionadas ao Heavy Metal. Devemos pensar de que maneira esse gosto pelo Metal é compartilhado, antes pela troca de fita cassete gravada de forma caseira do disco de vinil importados trocadas entre amigos e ou conhecidos, posteriormente a troca sendo feita através de CDs e DVDs e hoje por meio da internet. Hoje o próprio celular se transformou em uma ferramenta para ouvir músicas em MP3 no caminho da escola, faculdade ou do trabalho. Escuta-se música por onde se passa e com isso nos envolvemos com a música sem que percebamos.

As trocas pela internet não estão restritas ao conhecimento de novas bandas, mas a divulgação de shows, compras e vendas de ingressos e camisas. Existem ainda sites como o Whiplash ${ }^{3}$ e blogs sobre diversas bandas contendo informações sobre bandas clássicas e recentes. Conhecer a história das bandas, seus melhores álbuns, curiosidades sobre os seus integrantes. A internet possibilitou assistir shows com transmissão ao vivo de outros países, assistir a festivais consagrados com exibição simultânea. Ser metaleiro é a todo o momento estar atualizado. Além do som propriamente dito, nas redes sociais são vendidos, comprados ou trocados objetos relacionados à cena, como CDs, discos, camisas de bandas (algumas femininas customizadas), corpete, botas, coturnos, instrumentos musicais, ingressos, dentre outros. Os itens quanto à vestimenta são de grande importância nessas trocas, pois é um dos elementos que reconhecemos um metaleiro. Integrantes de bandas e fãs possuem vestimenta sobrecarregada de símbolos, como a cor preta, correntes e tachas metálicas. Em um show, o visual essencial é calça preta, coturno e uma blusa preta com ou sem estampa de banda.

Apesar das trocas proporcionadas pela internet, observamos a importância das trocas não virtuais, ou seja, a internet como ferramenta de trocas, como meio de organização de idas em shows e divulgação. Amigos que se unem para ir a alguns shows locais e em outros estados juntos, combinando a compra de ingressos e transporte. Muitos deles se encontram antes dos shows, seja em bares, seja no próprio ponto de ônibus ou combinando caronas até o evento. Alguns desses

${ }^{3}$ http://whiplash.net/ Site inaugurado em Junho de 1996que se transformou em um veículo de comunicação sobre Rock e Heavy Metal no Brasil e importante fonte de informações e curiosidades sobre bandas e seus integrantes. 
bares situados próximos aos shows pertencem a integrante de banda ou a amigos que simplesmente compartilham o gosto pelo Metal e cedem espaço para esse público criando um ambiente favorável aos membros desse grupo.

Em Juiz de Fora 4 , por exemplo, o bar The Rock's Studio Bar era local de encontro do público Metal e seu primeiro dono era o vocalista Tuka em parceria com o tecladista William Tassi ambos da banda Tuka's Band. Posteriormente o bar passou a pertencer ao guitarrista Felipe Rosa (chamado de Romarinho) integrante da banda Hard Desire. O bar além de servir bebidas e porções ao som de DVD's de shows de bandas clássicas fornece o aluguel de um estúdio para ensaio de bandas locais na parte superior do estabelecimento. O bar com estúdio se configurou como um espaço para ensaios e gravações das bandas, reuniões e bate-papo regados à cerveja. Atualmente o bar se encontra fechado. Outro bar que também é composto por bar e estúdio é o Maquinaria, porém neste estabelecimento a banda não fica escondida ensaiando, pois existe uma espécie de cabine com uma pequena janela em que o público sentado ou em pé tem a oportunidade de assistir. É chamado de Ensaio Aberto e como existe apenas uma pequena janela, a imagem da banda é projetada em duas paredes diferentes. $\bigcirc$ público escuta o som da banda, porém a banda não tem conhecimento da reação do público quanto ao seu som.

O público Metal também se reúne em shows em casas noturnas que cedem espaço para o público Heavy Metal, como o Cultural Bar, Galpão Lounge Bar, Bar Cai\&Pira e o Bar da Fábrica. Dentre as bandas que revezam para tocar nessas casas noturnas são: Hard Desire, Glitter Magic, Tuka's Band e a Crusher. Os integrantes possuem outros projetos como Acoustic n' Roll, banda composta de integrantes de outras bandas de Juiz de Fora que além dos instrumentos recorrentes do Metal contam também com três violões, uma viola e instrumentos de percussão para tocar cover de bandas clássicas famosas. Este projeto ajudou na aceitação do gênero em alguns bares, pois a ausência de guitarras torna o som menos barulhento, proporcionando um ambiente mais calmo e favorável para conversas.

\section{5 - Educação do ouvir}

${ }^{4}$ As informações sobre o cenário Heavy Metal em Juiz de Fora foram obtidas em pesquisa em andamento para a Dissertação de Mestrado "Música, juventude, corpo e emoção: perspectivas antropológicas sobre o Heavy Metal". 
Tim Ingold (2000) aborda o tema de como as pessoas compreendem o mundo por meio da experiência dos seus sentidos, ou seja, o indivíduo é capaz de ter contato com o mundo mediante "percepções". Assim como o caçador indígena que enxerga pegadas de animais que nós não perceberíamos devido a nossa falta de experiência, já que não temos essa mesma habilidade, ou porque não estarmos com nossos sentidos aguçados para perceber essas pegadas no ambiente. A diferença nas habilidades e percepções está relacionada à nossa experiência de desenvolvimento em um ambiente específico.

Em The perception of the environment (2000), Tim Ingold substitui o conceito diferenças culturais por diferença de habilidades. Por meio de um ajuste de habilidades de percepção e não construídos como era pensada anteriormente. Através da educação sensorial por meio da percepção fundamentada pela atenção. Assim sendo, a experiência de ouvir Heavy Metal e armazenar estas percepções possibilitam obter conhecimento musical por meio da sensibilidade.

A sensibilidade musical ao "educar a atenção" descrita por Tim Ingold (2000) é "aprender a ouvir". O Heavy Metal oferece aos novos membros do grupo trajetórias a serem percorridas de acordo com a experiência de cada um. Após o ingresso, o indivíduo aprimora o seu ouvir, como uma espécie de refinamento do saber sobre o som deste gênero, um aprendizado por meio da experiência de ouvir.

No aprendizado de ouvir o Heavy Metal, cria-se um sistema de valor. Esse valor está atrelado ao conhecimento sobre atitudes, gostos e música. Trata-se do conhecimento sobre as bandas mais famosas, os melhores álbuns dessas bandas clássicas. Refere-se também ao conhecimento da história do Heavy Metal e a história dessas bandas, sempre estar atualizado e realizar a troca desse conhecimento com os demais membros do grupo.

O "saber escutar" no Heavy Metal também está implicado no conhecimento de saber diferenciar os subgêneros dentro do Heavy Metal, não se trata de decorar os subgêneros a que cada banda pertence, mas ouvir uma música nunca escutada anteriormente e conseguir identificar através da maneira que os instrumentos e o vocal são executados e conseguir classificá-los. Ao ser capaz de fazer o reconhecimento o indivíduo recebe prestígio e valor diante dos demais membros do grupo. $\bigcirc$ aprendizado de ouvir Metal também permite reconhecer quando uma banda erra na execução da música, seja na execução dos instrumentos ou na letra e isso ocorre mesmo quando o indivíduo que percebeu o erro não possui nenhum conhecimento prévio sobre os instrumentos, ou seja, o conhecimento 
sobre as músicas transcende o conhecimento de saber tocar o instrumento, pois só pelo fato de estar familiarizado com o gênero, o metaleiro reconhece o erro.

A partir dessa absorção de conhecimentos e experiências cria-se uma hierarquia. $\bigcirc$ metaleiro que possui mais conhecimento sobre as bandas clássicas ou conhece bandas que os demais metaleiros não conhecem, têm experiências acumuladas em idas em shows de bandas famosas, este metaleiro tem mais prestígio do que os que não acumularam estes conhecimentos e experiências, ele está acima dos demais. Os outros membros o respeitam e tem interesse em ouvir sobre essas experiências.

Conforme analisado por Pelaez (2005) e discutido incialmente neste artigo, existe uma hierarquia quanto ao gosto pelos gêneros musicais em seu estudo. Porém existe ainda uma hierarquia quanto aos subgêneros do Heavy Metal, de forma que os indivíduos "progridem" ou amadurecem seu gosto musical, mudando assim de um subgênero para outro, mas discutir essa questão escapa ao que foi proposto neste artigo e seria necessária uma abordagem mais minuciosa para analisar todos os subgêneros do Heavy Metal e como seria essa hierarquia na visão de cada fã de determinados subgêneros.

Existe um amadurecimento de gostos no Heavy Metal. Após a descoberta da existência do "mundo" de subgêneros que ele abarca, os jovens fazem suas próprias escolhas de bandas, uma vez que o sujeito se conecta aos diferentes subgêneros. A transição entre os subgêneros acontece de formas variadas. No início todo metaleiro conhece as bandas clássicas como Led Zeppelin, AC/DC e Black Sabbath dentre outras através de amigos ou familiares, após essa fase ele vai conhecendo os demais subgêneros por conta própria ou indicação de algum conhecido. Após essa etapa o metaleiro percebe com quais subgêneros ele se identifica e com isso pode permanecer nesses subgêneros ou conhecer novos, uma vez que a cada dia surgem mais subgêneros. Existem casos em que o metaleiro permanece em determinado subgênero, mas flerta com outros.

O caminho trilhado pelo Heavy Metal segue por bandas que possuem diferenças quanto à maneira de tocar os instrumentos, caracterizando assim particularidades de cada subgênero. Músicas com velocidade na forma de tocar os instrumentos caracterizados como agressiva e "pesada" e uma valorização do instrumental por meio de solos, algo mais técnico.

O antropólogo Sam Dunn em seu documentário "Metal: A Headbanger's Journey" descreve toda a trajetória do Metal e cria uma árvore genealógica do Metal contendo 26 subgêneros, dentre eles estão: "Pre-Metal", "Progressivo", 
"Hard Rock", "Power Metal", "New Wave of British Heavy Metal", "Punk", "Doom Metal", "Glam Metal", "Thrash Metal", "Death Metal", "Funk Metal”, "Metalcore", "Grunge", "Post-grunge", "Gothic Metal", "First Wave of Black Metal", "Nu Metal" entre outros. Não é possível descrever todos os "metais" presentes no Heavy Metal, pois as combinações de som são infinitas. Os indivíduos que não estão inseridos no mundo do Metal não compreendem o prazer em ouvir Heavy Metal, esse gênero hostil e de difícil compreensão aos ouvidos inexperientes.

\section{6 - Considerações finais:}

Diante da noção de juventude abordada no artigo e posteriormente pensando a juventude e as relações intergeracionais "dentro do mundo do Metal", encontramos uma divisão entre os metaleiros: os velhos e os jovens. Os velhos permanecem jovens no sentido da vivência de experiências constantes no Metal, os quais possuem o sentimento de ser jovem por continuar participando deste cenário, assim como o fazia em sua adolescência, mesmo assumindo responsabilidades de uma vida adulta. E os jovens, os quais querem "amadurecer" ou "se tornar velhos metaleiros", ou seja, estes jovens tem o desejo de adquirir a experiência e o conhecimento sobre Metal dos mais antigos.

A presença de diferentes gerações convivendo no meio metaleiro parece um caso interessante para o debate sobre "juventudes" a ser analisado. A primeira impressão é a de complementaridade, ou seja, parece que o velho precisa do jovem para se sentir jovem, de perceber que a idade o tornou sábio sobre o Metal e que teve a oportunidade de ir a shows de bandas consagradas que já não existem mais, ou seja, suas experiências são valiosas para esses jovens. Para os jovens metaleiros esses velhos são fonte de conhecimento e experiência do Heavy Metal e é através deles que é possível conhecer a infinidade de bandas e subgêneros.

Os adolescentes dos anos 1980 que se identificaram com o Heavy Metal, possuem hoje entre 45 e 50 anos de idade e dentre eles a maioria continua neste cenário talvez não de forma tão intensa quanto em sua adolescência e poucos apenas "passaram" por esse gênero. Novas fases da vida surgem e com a vida adulta surgem obrigações e deveres. $\bigcirc$ Heavy Metal se enraíza na vida do adolescente de tantas formas diferentes, no som, na forma de se vestir e comportar e nas amizades proporcionadas pelo som, o que torna compreensível queestes indivíduos continuem ouvir metal mesmo navelhice. Esses adolescentes 
entraram na universidade, começaram a trabalhar, constituíram família e o amor pelo metal continuou presente em suas vidas. Permaneceram assistindo shows, apreciando novas bandas e novos subgêneros e acompanhando os acontecimentos desse cenário, sempre revisitando o Heavy Metal.

Além dos fãs mais velhos de Heavy Metal existem os ídolos mais velhos. As bandas clássicas mais famosas possuem integrantes com idade avançada entre os 40 a 65 anos. O cantor Ozzy Osbourne possui 70 anos e James Hetfield, vocalista do Metallica tem 55 anos e todos estão tocando com suas respectivas bandas atualmente fazendo turnês pelo mundo inteiro. O último álbum do Metallica, o "Hardwired... To Self Destruct". Com a idade sabemos de cor a discografia das bandas e isso segue até o estágio da velhice.

Espera-se ter apontado neste artigo a importância da relação entre juventude e música, e para aspectos fundamentais da socialização de jovens no Heavy Metal. Sendo um espaço de produção e compartilhamento de conhecimento e vivências, chamamos a atenção para como encontramos aí um modo especial de experienciar a "juventude" que conecta pessoas de diferentes faixas etárias no gosto por "sons pesados", que se aprende a ouvir e entender.

\section{Referências Bibliográficas:}

ABRAMO, H. W.. Considerações sobre a tematização social da juventude no Brasil. Revista Brasileira de Educação. (Número especial - Juventude e contemporaneidade, 2007), 5(6), 1997, p. 73-90

ARROYO, Margarete. Juventudes, músicas e escolas: análise de pesquisas e indicações para a área da educação musical. Revista da ABEM, Porto Alegre, n. 21, março 2009, p. 53-66.

,Margarete. "Apresentação"e "Jovensemúsicascomotemainves-tigativo". In ARROYO, Margarete (ed.): Jovens e Músicas: um guia bibliográfico. São Paulo: UNESP. 2013, p. 8-38.

ASSIS, Marcos Arcanjo de. Religião como variável para se pensar a juventude: um modo jovem de ser religioso. Revista Três [...] Pontos (UFMG), Belo Horizonte, v. 2, n.2, 2005 p. 55-62. 
CAMPOY, Leonardo Carbonieri. Trevas Na Cidade: O Underground Do Metal Extremo No Brasil. Universidade Federal do Rio de Janeiro. Rio de Janeiro. Dissertação de Mestrado. 2008.

COELHO, P. R. S. G.. BATENDO CABEÇAS: educação estética e política tecidas a partir do Heavy Metal; Dissertação (Mestrado em Educação) - Universidade do Estado de Minas Gerais; 2014.

CORDEIRO, D. S.; LIMA, C. A. F.; PEREIRA, C. S. S.. Identidade metaleira na construção de um espaço social na região do Cariri. In: Observatorium: Revista eletrônica de Geografia, v.2, n.5 - 38, nov. 2010, p. 21.

CHRISTE, I. Heavy metal: A história completa. São Paulo: Ed. ARX/ Saraiva, 2010.

DAYRELL, J. A Música entra em cena: o rap e o funk na socialização da juventude. Belo Horizonte. Editora UFMG, 2005.

FEIXA, Carles; PORZIO, Laura. Um percurso visual pelas tribos urbanas em Barcelona. In. PAIS, José Machado. (Coord.). O visual e o cotidiano. Lisboa: ICS/ Imprensa de Ciência Sociais, 2008.

FERNANDES, Fernanda Marques \& FREIRE FILHO, João. "Jovens, espaço urbano e identidade: reflexões sobre o conceito de cena musical". XXVIII Congresso Brasileiro de Ciências da Comunicação. Rio de Janeiro, UERJ, 5 a 9 de set./2005.

GARCIA, Amanda Veloso. O Rock Além do Som: uma abordagem antropológica. In. Anais do I Congresso Internacional de Estudos do Rock. Cascavel - PR, 2013. Disponível em http://www.congressodorock.com.br Acesso em: 04 dez. 2016.

GIDDENS, Antony. A Constituição da Sociedade. São Paulo: Martins Fontes, 1989.

INGOLD, T.. The Perception of the Environment. Essays on Livelihood, Dwelling and Skill. London, Routledge, 2000. 
KAHN-HARRIS, Keith. Extreme Metal: Music and Culture on the Edge. Oxford/ New York: Berg, 2007.

LOPES, Pedro Alvim Leite. Heavy Metal No Rio de Janeiro e Dessacralização de Símbolos Religiosos: A Música do Demônio Na Cidade de São Sebastião das Terras de Vera Cruz. Universidade Federal do Rio de Janeiro. Rio de Janeiro. Tese de Doutorado, 2006.

MORAES, L. L. Hordas do Metal Negro: identidades, práticas e discursos da cena Black Metal paulistana. I Congresso Internacional de Estudos do Rock. Universidade Estadual do Oeste do Paraná - UNIOESTE. Cascavel: Paraná, 2013.

PAIS, José Machado. Culturas Juvenis. Imprensa Nacional casa da moeda: Lisboa: Portugal, 2003.

PELAEZ, Neyde Carstens Martins. "A música do nosso tempo": Etnografia de um universo musical de adolescentes. Florianópolis. Dissertação de Mestrado em antropologia social. Universidade Federal de Santa Catarina, 2005.

PINTO, Tiago de Oliveira. Som e música. Questões de uma antropologia sonora. Rev. Antropol. [online]. Vol.44, n.1, 2001, p.222-286. Disponível em http://dx.doi. org/10.1590/S0034-77012001000100007. Acesso em: 04 dez. 2016.

PURCELL, Natalie J. Death Metal music: the passion and politics of a subculture. Jefferson, North Carolina: McFarland e Company, 2003.

WEINSTEIN, Deena. Heavy Metal: The Music And Its Culture. New York: Da Capo Press, 2000.

\section{Filmografia:}

METAL: A Headbanger Journey. Produção de Sam Dunn, Scot McFadyen e Jessica Joy Wise. São Paulo: Warner Home Video / Europa Filmes, 2005. 1 DVD (96 min.): DVD, PAL-M, son, color. Legendado. Port. 